\title{
Cuando la variedad diatópica se erige excepcionalmente en norma traductológica
}

\section{Cristian Díaz Rodríguez}

\section{(2) OpenEdition}

12 Journals

Edición electrónica

URL: https://journals.openedition.org/cher/1000

DOI: $10.4000 /$ cher. 1000

ISSN: 2803-5992

\section{Editor}

Presses universitaires de Strasbourg

\section{Edición impresa}

Fecha de publicación: 12 diciembre 2019

Paginación: 171-187

ISBN: 979-10-344-0057-7

ISSN: 1968-035X

\section{Referencia electrónica}

Cristian Díaz Rodríguez, «Cuando la variedad diatópica se erige excepcionalmente en norma traductológica», reCHERches [En línea], 23 | 2019, Publicado el 13 octubre 2021, consultado el 17 noviembre 2021. URL: http://journals.openedition.org/cher/1000 ; DOI: https://doi.org/10.4000/cher. 1000 


\title{
Cuando la variedad diatópica se erige excepcionalmente en norma traductológica
}

\author{
Cristian Díaz Rodríguez ${ }^{1}$
}

\begin{abstract}
U
na de las mayores dificultades que presenta la traducción es la de ser capaz de ofrecer, en la lengua meta, un texto que respete la pertinencia y la riqueza funcional e idiosincrática de la que goza el texto primigenio, pues «el traductor tiene que reflejar en su versión cualquier desviación del lenguaje natural» (Newmark 1992: 37). En este sentido, el traductor debe prestar especial atención a las manifestaciones variacionales de las que se nutre el texto (cfr. Mayoral Asencio 1999). Así, por ejemplo, el uso deliberado de un determinado arcaísmo no puede, en modo alguno, considerarse un gesto baladí. De igual forma, las variaciones diastráticas y diafásicas son tanto más importantes cuanto que el registro de lengua forja, en muchos casos, la personalidad e, incluso, la identidad de los personajes y de las sociedades de la diégesis. Reviste de especial interés la traducción de las variedades diatópicas que cohabitan en la lengua origen (Uclés Ramada 2016), pues su extrapolación interlingual pasa, por lo general, por asimilar, de manera bastante arbitraria, dos subcomunidades de hablantes, no necesariamente en función de su similitud estrictamente lingüística, sino en función de la relación que dichas comunidades de hablantes mantienen con respecto a una supuesta norma monocéntrica.

En este artículo abordaremos un caso excepcional del tratamiento que recibe la variación diatópica en la traducción francés-español. Lejos de recurrir al constructo normativo de «español estándar» como lengua meta, se opta por erigir la variedad lingüística canaria en norma, a pesar de que el texto original, con la salvedad de algunas ocurrencias léxicas y una acentuación que da buena cuenta de los rasgos fonológicos de la comunidad de hablantes en la que se inscribe el autor (el francés del Mediodía), parece responder a un «francés estándar», desprovisto de dialectismos. La excepcionalidad de dicha elección metodológica se justifica por dos razones principales. Por un lado, el público
\end{abstract}

1 Cristian Díaz Rodríguez, Université de Strasbourg, CHER, ORCID: 0000-0002-75197376 
al que se dirige la traducción de la obra es principalmente canario (la editorial LeCanarien solo distribuye en Canarias). Por otro, damos por supuesto que, al haberlo aprendido in situ, el español de Sabino Berthelot se inscribía dentro de la norma canaria. No obstante, si, contrariamente a nuestra hipótesis, el agente consular francés hubiera contado con una base sólida en español antes de su llegada a las Islas, su larga estancia en Canarias habría influido forzosamente en su forma de expresarse. Además, las fuentes documentales auxiliares en las que se han apoyado las investigaciones que subyacen bajo esta obra (publicaciones parciales de su obra en la prensa local, principalmente) nos permiten aseverar dicha afirmación.

Comenzaremos exponiendo los rasgos biográficos más destacados del autor, así como las particularidades de la concepción de la obra. A continuación, se comentarán las dificultades encontradas a la hora de transcribir y traducir el compendio de memorias e informes consulares, y el proceder filológico seguido para el restablecimiento de ciertos pasajes: identificación de la voz del autor, cotejo de textos autotraducidos, consulta de su producción periodística divulgativa, etc. Este ejercicio de naturaleza más filológica que traductiva nos ha llevado a reconocer ciertos patrones que caracterizan, además de su estilo y de su fraseología particular, su inclusión dentro de la norma de la modalidad lingüística canaria. De ahí que, en aras de garantizar una mayor fidelidad del texto meta, se haya puesto especial esmero en el respeto de los rasgos morfosintácticos y léxicos que caracterizan el habla canaria.

\section{Sabino Berthelot: un personaje excepcional}

El carácter polifacético del agente consular (1848-1867) y, posteriormente, cónsul $^{2}$ de Francia en las islas Canarias (1867-1874), Sabino Berthelot, hace que todo intento de descripción de este personaje singular y esencial de la historia del Archipiélago sea reduccionista y sesgado. Como destaca Le Brun ${ }^{3}$, «Sabino Berthelot fue marinero, comerciante, científico y diplomático. Actuó a veces estando al servicio o comisionado del Estado, otras veces de forma libre» (2016: 29). La «identidad múltiple» (Le Brun 2016: 29) de este ilustre personaje, además, vendría alimentada por sus labores como profesor y director del

$2[\ldots]$ François Guizot tomó la decisión de nombrar a Sabino Berthelot como administrador temporario de la agencia santacrucera [...]. Sabino Berthelot consiguió la titularidad algunos meses más tarde (14 de abril de 1848) [...]. Posteriormente, Sabino Berthelot ascendió al rango de cónsul honorario de segunda clase (decreto imperial del 25 de agosto de 1861), cónsul de segunda clase (decreto del 14 de agosto de 1867) y cónsul de primera clase (decreto del 31 de marzo de 1874). (Le Brun y Díaz Rodríguez 2018: 28).

3 En Un francés entre guanches. Sabino Berthelot y las Islas Canarias, la autora hace una profunda revisión de la biografía del agente consular y, más tarde, cónsul de Francia en las islas Canarias, así como un detallado repaso a la producción científica y a la labor diplomática de Sabino Berthelot. 
Liceo de La Orotava, administrador del Jardín de Aclimatación de La Orotava, historiador, etnólogo, miembro de diversas sociedades científicas de la época - entre ellas la Sociedad de Geografía de París, de la que fue secretario entre 1835 y 1842, y la Sociedad de Etnología, de la que fue fundador en 1845-, redactor de artículos periodísticos de carácter científico, divulgativo o social, y, como buen naturalista-empirista, cabe suponer que, para llevar a cabo sus ensayos científicos, desempeñó incluso labores agrarias fundamentales. Todo esto hacen de este francés nacido en Marsella, aunque canario de adopción ${ }^{4}$, una figura excepcional sin parangón.

Como representante diplomático de Francia en las Islas procuró sacar adelante proyectos que revirtieran en el interés del Estado francés. Se involucró sobremanera en el desarrollo de la educación ( $v . g$. creación del liceo orotavense), de la industria local ( $v . g$. desarrollo de la industria de la cochinilla, de la seda...), de la botánica ( $v . g$. jardines de aclimatación, estudios sobre las especies madereras de las Islas) y del comercio ( $v . g$. creación de puertos francos), como se aprecia en las diferentes memorias e informes consulares recopilados en el libro. Todo ello sin socavar, en modo alguno, el beneficio que eventualmente pudieran sacar las Islas, velando de este modo por el desarrollo y el progreso del Archipiélago. Prueba de ello es su activa participación en las Reales Sociedades Económicas de Amigos del País o su labor periodística como divulgador científico y creador de opinión.

Dentro de su profusa producción científica destacan obras como De la pêche sur la côte d'occidentale d'Afrique et des établissements les plus utiles aux progrès de cette industrie (1840), Antiquittés canariennes (1879) y, sobre todo, Histoire naturelle des îles Canaries, redactada en colaboración con Philip Barker Webb (1835-1850). La importancia de estas obras, más allá de sus excepcionales aportes científicos en temas tan diversos como la historia, la etnografía, la antropología o la botánica, reside en el hecho de que, por primera vez, la comunidad científica internacional, especialmente la europea, toma conciencia de las singularidades, cuando no de las excepcionalidades, de las islas Canarias.

\section{Cuando el fin justifica la edición}

La obra que nos ocupa, Informes y memorias consulares de Sabino Berthelot (1847-1874), constituye una compilación de informes, notas, memorias y otros escritos gubernamentales (un total de dieciocho unidades documentales) redactados por Sabino Berthelot mientras este ostenta la representación diplomática de Francia en el Archipiélago, y remitidos a diferentes direcciones departamentales del Ministerio de Asuntos Exteriores francés, de ahí que cada fuente documental vaya precedida de la misiva que acompañaba cada informe o memoria. En estos documentos, el agente consular, en tanto que informante

4 En 1876 es nombrado hijo adoptivo de la Santa Cruz de Tenerife (cfr. Le Brun 2016: 16). 
comercial $^{5}$, da cuenta al Estado de cuantas iniciativas de carácter comercial o administrativo se ponían en marcha en el territorio en el que desempeñaba sus prerrogativas, y que afectaban, aunque fuese tangencialmente, a los intereses del Estado. Como se señala en la introducción de la obra, la naturaleza de los documentos recogidos es de diversa índole: informes periódicos sobre movimientos de comercio y la navegación (informes trimestrales, memorias anuales), boletines, notas o informes ocasionales, cuya redacción obedecía a la imperiosa necesidad de informar sobre un suceso excepcional (malas cosechas, invasión de plagas, etc.). Además de la comunicación de los datos estadísticos recabados en el país, labor inherente a la función consular, en la obra se incluyen memorias e informes que manan del interés personal de Sabino Berthelot, en los que, a veces, se incita al Gobierno francés a tener en cuentas ciertos progresos, sobre todo agrícolas, llevados a cabo en Canarias; o se alerta sobre la pujanza de ciertas proto-industrias, que podrían ser interesantes para Francia. Las unidades documentales relacionadas con iniciativas particulares de Sabino Berthelot se han acompañado de una ficha introductoria que contextualiza el proyecto.

La vocación con la que nació esta obra fue la de establecer un corpus documental que sirviera como punto de partida para futuras investigaciones en historia, política económica, economía histórica, botánica, filología (análisis del discurso)..., relacionadas con el área geoestratégica de Canarias durante el siglo XIX. De hecho, la condición ultraperiférica del territorio insular hace que, en muchas ocasiones, los investigadores no tengan fácil acceso a estas fuentes documentales conservadas en archivos franceses. Además, la (in)competencia razonable en la lengua francesa de muchos investigadores puede suponer, sin duda, un escollo para desentrañar toda la importancia de un documento. En aras de solventar estos dos inconvenientes, en el momento de concebir la edición de la obra, se decidió optar por una publicación bilingüe, en la que se recogiera la transcripción de las unidades documentales seleccionadas, así como la de la carta que las acompañaba, y sus correspondientes traducciones en español.

\section{Especificidades de la transcripción}

Como se menciona en el título de la obra, las fuentes documentales recogidas fueron redactadas en el período comprendido entre 1847 y 1874 . Al tratarse de documentos de la segunda mitad del siglo XIX, se comprenderá, sin mucha dificultad, que el estado de conservación de los mismos no es todo lo bueno que se hubiera deseado. Los documentos que con fortuna se han podido recuperar están, en su mayoría, muy estropeados: roturas internas, tinta borrada, etc., lo que imposibilita muchas veces la trascripción de algunas palabras o pasajes, identificados en la trascripción mediante la marca «[ilegible]». A esto hay que añadir que tan solo cuatro documentos de los que se incluyen en la obra llegaron

5 En el corpus documental se ha hecho abstracción de todas aquellas misivas de carácter personal, en las que se solicitan permisos, excedencias, promociones, etc. 
a publicarse íntegramente, el resto se publicó solo parcialmente o permaneció inédito. En otras palabras, la mayor parte de unidades documentales ha sido transcrita a partir de versiones manuscritas o de borradores ${ }^{6}$.

Las investigaciones llevadas a cabo en distintos archivos gubernamentales franceses no nos permitieron reconstituir, en su totalidad, el corpus de los documentos escritos por Sabino Berthelot en el ámbito de su correspondencia con la Dirección de Consulados y los Asuntos Comerciales. En el Centro de los Archivos Diplomáticos de Nantes, donde se conservan los llamados archives des postes, encontramos, con la documentación procedente del antiguo Viceconsulado de Francia en Santa Cruz de Tenerife, los borradores de algunos informes, que nos ayudaron, en algunos casos, a colmar el vacío. Asimismo, varias de las memorias remitidas de forma espontánea por Sabino Berthelot al ministro de Asuntos Exteriores llegaron a ser publicadas. En estos casos, cuando la localización de los manuscritos o los borradores no ha sido posible, optamos por transcribir y traducir las versiones impresas, publicadas en diferentes revistas de la época. (Le Brun y Díaz Rodríguez 2018: 35)

En todos los casos, se han reducido al mínimo las modificaciones introducidas: se han conservado las faltas ortográficas (señaladas mediante «[sic]»), se han conservado las incoherencias y vacíos sintácticos, así como los hispanismos, se han respetado los arcaísmos residuales (v.g. tems, fesant, ameilloration, plurales en -ens y -ans), etc. En cualquier caso, las modificaciones introducidas se han limitado a aquellas preconizadas por la École nationale des chartes para la edición de textos decimonónicos (Nougaret y Parinet 2015): uniformización de las tildes ${ }^{7}$, desarrollo de las abreviaturas, separación de las palabras y actualización del uso de mayúsculas.

Además, al tratarse en muchos casos de textos borradores, abundan las reformulaciones, las rectificaciones y los borrones propios del proceso de redacción. En este sentido, la obra que nos ocupa constituye una auténtica excepción desde el punto de vista editorial, pues, dado que es tan importante el texto final que se ofrece al lector/investigador, como el proceso de formulación en sí (prioridad dada a los elementos, reformulaciones intensificadoras, atenuadoras, de cortesía...), se ha optado por trascribir las trazas de dicho proceso de escritura, valiosísimas desde el punto de vista del análisis del discurso.

Otro aspecto fundamental que se ha tenido en cuenta a la hora de editar el libro es el esmero con el que se ha tratado de cuidar la inclusión de los abundantes elementos paratextuales, porque, en muchos casos, corresponden

6 Solo en el caso de las unidades documentales De l'acclimatation en Algérie des principales essences forestières des îles Canaries y Nouveau système de pêche se ha tenido que transcribir la versión publicada, pues, no se han localizado las versiones manuscritas.

7 Aunque es cierto que el origen marsellés de Sabino Berthelot queda patente a la hora de acentuar, muchas veces dubitativamente, con acento grave algunas $e$ cerradas, consideramos que su señalización mediante [sic] hubiera dificultado la lectura y la comprensión del texto. 
a imperativos exigidos en la redacción de la correspondencia establecida con el Ministerio de Asuntos Exteriores: reproducción de membretes, indicaciones de la fecha de redacción del documento, la sección ministerial a la que estaba dirigido y número de carta, reproducción espacial de las memorias (inclusión de epígrafes o de puntos de contenido en el margen izquierdo, fuera del cuerpo del texto), respeto de los colores de las tintas empleadas en el texto, sellos, cuños, planos, indicaciones sobre la firma y el firmante, indicaciones escritas a lápiz en el momento del envío o de la recepción del documento, etc.

\section{Proceso de traducción: en busca del restablecimiento de la voz del autor}

La traducción de fuentes consulares representa un auténtico reto para el traductor, pues el público meta al que va destinado la obra responde a dos perfiles que, si tenemos en cuenta sus intereses, podrían considerarse enfrentados. Por un lado, se encuentra el lector general, que busca saciar su sed de conocimiento a través de una obra especializada. Por otro, nos encontramos con un lector experto, versado en los temas tratados, quien utilizará la compilación de textos como un producto semielaborado a partir del cual procederá a hacer sus propias investigaciones. Evidentemente, el tipo de traducción que se adapta en mayor medida al primer tipo de público es el que responde a un enfoque traductológico basado en la teoría interpretativa o del sentido (Seleskovitch y Lederer 2014 [1984]), tan practicado en la traducción comercial. Según este enfoque, el traductor no traslada las palabras sino el sentido global de la obra, es decir, el traductor, que solo debe ser fiel al sentido del texto, puede ser al mismo tiempo autor del texto meta, ya que, al no tener que respetar la forma, se puede permitir licencias estilísticas, adaptaciones afines a la localización, supresión de pasajes, compensación de intención en otras partes del texto, reformulaciones...

Sin embargo, el público investigador aspira a tener un texto lo más próximo posible al texto original, aséptico, desprovisto de la acción del traductor, un texto en el que solo se reconozca la voz del autor primigenio. En este tipo de traducciones, se preconiza la traducción casi palabra por palabra: un cambio en la formulación, por muy pequeño que sea, constituye una traición ${ }^{8}$ al significado o a la intención del autor primero, pues esto implicaría una tematización o una rematización errónea de un elemento al que el autor original no le concedía dicho papel. Se deben respetar las incoherencias semánticas, los vacíos sintácticos, los contrasentidos...

8 En este sentido, la aspiración por parte de un traductor de documentos consulares se acercaría, en cierta medida, a las preconizaciones jeronimianas: «Si les débats qui entourent la notion de fidelité en traduction ont parfois encore la vie dure, et si l'acte même de traduire est encore trop souvent entache de suspicion, c'est très certainement en raison des origines mêmes de l'acte de traduire, dont la genèse est à explorer du côté de la traduction des textes religieux, pour lesquels saint Jérôme tout comme Philon d'Alexandrie préconisaient la traduction littérale, seule méthode apte à ne pas 'altérer les textes sacres' (Oustinoff 2003: 28)»(Collombat 2012: 14). 
La dificultad, como se habrá podido deducir, reside, pues, en encontrar un tipo de traducción que constituya un perfecto equilibrio entre la traducción comercial y la traducción literal. Si tenemos en cuenta el enfoque traductológico del escopo (Reiss y Vermeer 1996), según el cual la finalidad del texto traducido (el proyecto) justifica el tipo de traducción llevada a cabo, el texto meta no representa un fin per se, sino, más bien, un medio. En nuestro caso, esto pasa por ser lo más fiel posible al texto, siempre y cuando se respete la gramaticalidad y la idiomaticidad del texto meta. Para ello, se ha optado por trasladar el texto a un español contemporáneo, pues la conservación del lenguaje decimonónico podría haber dificultado la lectura y el entendimiento del texto. Evidentemente, hemos estados vigilantes para que en el proceso de actualización del español no se incurriera en anacronismos. De igual forma, en la traducción, se han conservado los anglicismos presentes en la versión francesa del documento, pues representa un posicionamiento particularmente significativo por parte del autor (v.g. steamers). Con la finalidad de depurar el texto y facilitar la lectura, se ha optado por eliminar los tachones y las reformulaciones del texto traducido?.

En cuanto a la norma lingüística del español seleccionada para la traducción, se ha optado por la modalidad diatópica canaria. Esta decisión realmente excepcional se justifica, fundamentalmente, por dos motivos. Por un lado, el nicho de lectura al que va destinado esta obra se encuentra, principalmente, ubicado en Canarias, ya sean investigadores relacionados con esta área geoestratégica, $o$ lectores no especializados. Además, la editorial LeCanarien no distribuye fuera de Canarias, con lo que el lector potencial se restringe nuevamente a las Islas. Por otro lado, en nuestra intención de ser lo más fiel posible al texto original, hemos llegado a la conclusión de que Sabino Berthelot, quien seguramente no hablaba español antes de su primera llegada a Canarias, tuvo que aprender esta lengua en el Archipiélago, y, por tanto, haber adoptado la norma lingüística insular. Esta suposición de partida se ha visto corroborada mediante una labor de peritaje lingüístico, a través del cotejo de sus textos manuscritos con publicaciones que se hicieron, a veces de forma anónima y otras bajo el pseudónimo de Un amigo del país, en la prensa local (principalmente en Eco del Comercio y La Aurora), y que coinciden parcialmente con los datos comunicados por el cónsul al Estado francés.

\section{Tres caligrafías, una sola voz}

Como era costumbre, la escritura autógrafa del agente consular en la redacción de la correspondencia administrativa era relativamente excepcional si se comparaba con la que redactaban de su puño y letra los secretarios. En el caso de nuestro corpus documental, además de la escritura de Sabino Berthelot

9 Señalábamos anteriormente que estas formulaciones tenían un papel fundamental desde un punto de vista filológico, en concreto, desde el ámbito del análisis del discurso. Ahora bien, creemos que cualquier tipo de investigación que se quiera hacer en esta parcela de la disciplina lingüística tendrá que partir de la fuente original, es decir, del texto en francés, y no de la traducción. 
(identificada en cuatro cartas y cuatro documentos analíticos), reconocemos, hasta en veinticuatro ocasiones, la de su secretario Joseph Désiré Dugour (doce cartas y doce documentos) y, en una única memoria, la de su secretario Henri Bretillard.

En los primeros tiempos, Sabino Berthelot escribía él mismo sus cartas e informes, pero empezó a dejar que otros lo secundaran en esta tarea a partir de 1850. Con respecto a la correspondencia, los secretarios pasaban a limpio las cartas que luego él firmaba. Lo mismo ocurría con los informes, las notas y las memorias. El cotejo del borrador autógrafo de la memoria Considérations sur l'établissement des ports-francs dans l'archipel canarien (1852) con su versión definitiva, copiada por Henri Bretillard, pone en evidencia la total conformidad de los dos textos entre sí desde el punto de vista del contenido, aunque también la libertad que se tomaba el secretario para adaptar la lengua empleada por Sabino Berthelot a su propio sistema ortográfico. En cuanto a Joseph Désiré Dugour, ya señalamos en un trabajo anterior los interrogantes que suscita su colaboración. No se puede descartar una eventual contribución de su parte a la redacción (y no simplemente a la transcripción) de diversos documentos. [...] De ahí la duda acerca de la autoría real de algunas cartas de la correspondencia consular y comercial. (Le Brun y Díaz Rodríguez 2018: 33-34)

Si bien es cierto que la intervención de cada uno de los autores dota al texto de su estilo, su expresión y su fraseología particular, en nada cuestiona la decisión metodológica de erigir la modalidad lingüística canaria como norma traductológica, pues es de suponer que ambos secretarios, tal y como había pasado con Sabino Berthelot, hubieran aprendido el español in situ o, al menos, que la variedad diatópica en la que se hallaban inmersos ${ }^{10}$ hubiera influido en su forma de hablar.

\section{Cuando el traductor se convierte en filólogo}

Como se ha señalado previamente, Sabino Berthelot, además de expresarse en su lengua madre, el francés, también lo hacía en español. La competencia del cónsul en el manejo de esta lengua no se deduce tan solo de la práctica diaria a la que presuntamente le obligarían sus funciones diplomáticas en un territorio hispanoparlante, sino que también disponemos de fuentes documentales localizadas en la prensa de la época que así lo atestiguan. Muestra de su labor periodística-divulgativa podría ser, por ejemplo, el hecho de que:

[...] entre finales de 1847 y la primavera de 1848, Sabino Berthelot había sido uno de los colaboradores ocasionales de la revista tinerfeña La Aurora. En marzo de 1848, había publicado en dicha revista, bajo el seudónimo Un Amigo del País,

10 Cuando en 1816 Alexandre Bretillard es nombrado agente consular de Francia en las islas Canarias, su hijo, Henri Bretillard, apenas cuenta con 11 años de edad (Tous Meliá 2013). En cuanto a Joseph Désiré Dugour, el barco que lo trasladaba junto a su familia a América naufraga en 1827 frente a las costas africanas, desde donde son conducidos a Santa Cruz de Tenerife. En ese entonces, el joven Dugour contaba con tan solo 13 años (Gaviño de Franchy 2010). 
unos tres artículos relacionados con la sericicultura canaria. (Le Brun y Díaz Rodríguez 2018: 460)

El cotejo del contenido de varios artículos firmados por «Un Amigo del País» con los escritos oficiales de Sabino Berthelot no deja lugar a dudas sobre su autoría, puesto que, en muchos casos, aunque no se puede hablar realmente de autoplagio, ya que supondría un anacronismo, sí que nos enfrentamos a un caso flagrante de autotraducción. Como se comprenderá, en nuestro afán por reestablecer lo más fielmente la voz del cónsul, era necesario recabar todos los textos escritos en lengua española por este autor. El problema es que, junto con los textos firmados con el susodicho pseudónimo, se encontraban otros, en principio anónimos, que, tras una evaluación profunda del contenido y del estilo, también resultaron ser de autoría sabiniana. Esta labor de peritaje lingüístico, en la que el traductor se viste de filólogo para reconocer en los textos la voz trasladada del autor no deja de ser una excepción en el ámbito de la traducción. De hecho, este proceder ha permitido dar cuenta del estilo y de la particular fraseología de Sabino Berthelot. Términos que, en principio, suponían un auténtico desafío para el traductor, como es el caso de caravansérail, que, al no contar con una monolexía equivalente en español, hubiera obligado al traductor a recurrir a paráfrasis del tipo «lugar concurrido por extranjeros», cuentan con un equivalente traductológico explícito en los artículos publicados en prensa: parador del navegante. De igual forma, se ha podido conservar la intención del autor al no traducir de forma literal palabras como prospérité-prosperidad, développement-desarrollo, las cuales, en las producciones periodísticas de Sabino Berthelot, quedan resueltas, en la mayoría de casos, mediante un mismo término: progreso. Por último, cabe destacar que, desde el punto de vista terminológico, el hecho de contar con algunas traducciones validadas por el propio autor nos ha simplificado enormemente algunas dificultades terminológicas relacionadas con nombres científicos de peces, de especies arbóreas, etc.

\section{La excepcionalidad de la elección de una norma traductológica periférica}

Como se viene señalando a lo largo de todo el artículo, el carácter excepcional de la traducción mana principalmente del hecho de haber elegido como norma traductológica la propia de una variedad diatópica del español: la modalidad lingüística canaria, decisión que, según hemos justificado, está más que fundamentada.

La modalidad lingüística canaria se suele incluir dentro de las variedades atlánticas del español. Es sobre todo su realización fónica (cfr. Almeida y Díaz Alayón 1988) la que de manera más evidente aleja el habla canaria del español europeo que se habla en el centro y en el norte de la Península:
a. seseo generalizado
b. realización mayoritaria de la /-s/ en posición predorsodental
c. aspiración de la /-s/ en posición implosiva
d. aspiración de la $\mathrm{h}$
e. ablandamiento de la velar /x/ 


\section{f. sonorización y adherencia de la /ch/}

Evidentemente, el carácter escritural de la obra hace imposible que, en el texto meta, se tengan en cuenta dichos aspectos, pues, como hemos señalado anteriormente, el texto primigenio carece de estructuras dialógicas, las cuales habrían permitido reflejar eventualmente ciertos aspectos fonético-fonológicos ${ }^{11}$ de la variedad lingüística canaria.

En cuanto a los rasgos morfosintácticos que caracterizan el español de Canarias (cfr. inter alii Catalán 1986, Ortega Ojeda 2016), se debe tener en cuenta que es nuevamente el carácter consular y comercial de las memorias e informes reunidos en esta obra lo que no permite la inclusión de rasgos morfosintácticos propios del registro popular del habla canaria, como podrían ser la sustitución de las formas propias del imperativo por las del presente de indicativo (v.g. Me recogen todo esto vs Recójanme todo esto), ciertas asimilaciones (v.g. Salimos de su casa $y$ *lleguemos hasta el camino nuevo), anteposición del adverbio más al coocurrir con los indefinidos nada, nadie y el adverbio nunca (v.g. más nadie, más nada, más nunca) ${ }^{12}$, anteposición del sujeto de infinitivo y gerundio ( $v . g$. ¿yo ir a comer a su casa? Nunca, él viendo cómo me caía y sin hacer nada). Aun así, como elementos morfosintácticos representativos de la norma canaria culta, la traducción se caracteriza por:

a. ausencia de la realización de la forma de segunda persona del plural vosotros y de sus formas adjuntas: estas han sido substituidas por ustedes y sus correspondientes formas átonas. Además, se ha tenido en cuenta la repercusión que este uso tiene en la selección de las diferentes formas verbales ${ }^{13}$.

11 Los rasgos fónicos que acabamos de citar caracterizan un estado del habla canaria del siglo XIX, de manera que todavía no se aprecian fenómenos generalizados en la actualidad, como podría ser el yeísmo. De igual forma, dado el carácter de los textos reunidos, no serían pertinentes las particularidades fónicas que caracterizan a ciertos sociolectos del espectro canario (cfr. Almeida y Díaz Alayón 1988): asimilación (y posterior aspiración) de la $\mathrm{r}$ implosiva al coocurrir con una líquida o una nasal, confusión de ly r, caída de la /-d-/ intervocálica, caída de la /d/ final, etc.

12 Estaríamos en este caso frente a una clara influencia de la comunidad portuguesa asentada en las Islas desde su conquista hasta el siglo XVI sobre el español hablado en Canarias.

13 Sin embargo, como señala Ortega Ojeda: «[...] conviene aclarar que el pronombre vosotros y sus implicaciones morfológicas y sintácticas (aunque con alguna pervivencia antigua, como el uso de vos por os o el de alguna forma verbal) constituyen un rasgo tradicional de algunas zonas del Archipiélago. En concreto, en la isla de La Gomera y, más precariamente y entre personas de edad avanzada, en puntos de Tenerife y La Palma, el fenómeno presenta todavía una apreciable vitalidad. Este rasgo minoritario empieza a mostrar signos claros de resquebrajamiento, incluso en zonas como La Gomera, sin duda por el influjo de la norma canaria general y porque el mismo crea, al ser interpretado mecánica y erróneamente por muchos como una deslealtad hacia lo «canario», una enojosa asimilación con los hablantes peninsulares.» (2016: 11) 
b. ausencia de leísmo, loísmo y laísmo: incluso en el caso del leísmo aceptado por la Academia (cfr. NGLE 2009), en el que la forma le sustituye a un complemento objeto que denota a un hombre ${ }^{14}$.

c. uso preferente del pretérito perfecto simple o indefinido frente a la forma compuesta: tanto en el caso de expresión de acciones ocurridas en un pasado remoto como aquellas que tuvieron lugar en un pasado inmediato ${ }^{15}$.

d. uso generalizado del diminutivo construido con el sufijo -ito

e. uso generalizado del sufijo -ero para la denominación de especies hortofrutícolas

En muchos jardines de la isla, especialmente en el hermoso y fértil valle de La Orotava, el guayabero, la palmera, la anona, la palmera datilera, las plataneras y el árbol del café entremezclan sus ramas con las higueras, los morales, los melocotoneros, los manzanos y demás árboles frutales de nuestras regiones. (Le Brun y Díaz Rodríguez 2018: 468)

Como se puede apreciar, los rasgos morfosintácticos característicos del español de Canarias, aunque presentes en nuestra traducción, son poco relevantes. No ocurre lo mismo con el léxico empleado a la hora de traducir términos generales $\mathrm{y}$, sobre todo, denominaciones vernáculas que dibujan un espacio referencial único: el canario ( $v . g$. gofio, malpaís, caldo verde, barbusano, malvasía, pajada, etc.). Así lo señala Ortega Ojeda cuando apunta que:

De los aspectos del lenguaje, suele ser el léxico el más definitorio de una región o zona dialectal. Su propia esencia sociocultural hace que sea ésta la vertiente más vinculada a la experiencia, al mundo, por lo que el vocabulario una sección importante de él suele ser tan distinto como diferentes sean los aspectos naturales y culturales del espacio geográfico de que se trate. (2016:13)

Además de conservar fosilizaciones léxicas, que, en el español peninsular, pueden considerarse arcaísmos (bravo ='furioso', curioso ='cuidadoso', etc.), y términos prehispánicos o guanchismos, cuyo uso en la lengua se ha conservado hasta nuestros días (baifo, tajinaste, tabaiba, etc.), presentes, sobre todo en la toponimia (Anaga, Icod, Abona, etc.); el léxico canario cuenta con numerosos americanismos (guagua, guanajo, machango, etc.) y préstamos de otras lenguas, sobre todo anglicismos (queque, naife, etc.) y portuguesismos (magua, liña, jeito, maresía, etc.), cuya introducción se explica por la situación geoestratégica de Canarias, como cruce marítimo de tránsitos transatlánticos de mercancías y personas, y, por tanto, crisol de culturas. A pesar de que los períodos de introducción en el habla canaria varían sustancialmente, es posible que términos

14 El leísmo de cortesía es un fenómeno de relativamente reciente aparición entre los hablantes canarios.

15 Como señala Ortega Ojeda: «El pretérito perfecto, en cambio, se utiliza para expresar acciones reiteradas o durativas e imperfectas que, iniciadas en el pasado, se prolongan (o prolongan sus efectos) hasta el presente («Este año no ha llovido nada», "yo he estado varias veces en Madrid»)»(2016: 12). 
de diversa procedencia cohabiten ya desde el siglo xIx en el habla canaria, de manera que, en un solo párrafo, pueden coexistir portuguesismos (millo $\left.{ }^{16}\right)$, guanchismos $\left(\right.$ gofio $\left.^{17}\right)$ y galicismos (guanches $\left.{ }^{18}\right)$ :

Sin embargo, debe ser considerable si a la harina de trigo destinada a la elaboración de pan, se suma la harina de millo y de otros cereales, que los campesinos acostumbran a comer después de haberlas tostado, y que denominan gofio, como lo hacían los antiguos guanches. (Le Brun y Díaz Rodríguez 2018: 132)

En aras de respetar el estado de lengua representativo de las Islas en el siglo xix se ha verificado el uso de los canarismos léxicos empleados en la traducción en el Diccionario Histórico del Español de Canarias (DHECan). A modo de ejemplo, se muestran a continuación algunos de los canarismos utilizados en la traducción de los informes y memorias consulares:

16 A pesar de que tradicionalmente se haya considerado un portuguesismo, la información recabada en el DHECan presenta este término, que designa tanto a la planta gramínea del maíz (Zea mays) como a su semilla, como un occidentalismo peninsular, común en el portugués, el gallego, la zona salmantina y el canario. En Canarias, su uso se encuentra documentado desde 1609.

17 Esta voz prehispánica designa la harina hecha a partir «de millo, trigo o cebada tostados. El elaborado con cebada fue el único conocido por los antiguos habitantes de las islas. Se ha hecho también de otros granos, como garbanzos, arvejas, chochos o semillas de cosco e incluso raíces de helecho.» (DHECan). Se encuentra documentada en Canarias desde 1495.

18 Esta voz, que designa a los aborígenes de Tenerife, y por extensión a los de Canarias se documenta en las Islas desde 1498. Aunque durante mucho tiempo se pensó que se trataba de un término prehispánico, otras hipótesis recientes ven en el término guanche un galicismo introducido durante la época normanda, mediante el cual, de manera metonímica, se nombra a los habitantes de Canarias a partir de una actividad característica de los mismos: esquivar piedras, verbo que en francés medieval venía representado mediante la forma verbal guenchir y el sustantivo guenche (guanche). 
Tabla 1: Propuesta de traducción a través de términos propios del léxico de las Islas.

\begin{tabular}{|c|c|c|c|}
\hline Canarismo & DHECan & $\begin{array}{c}\text { Texto fuente } \\
\text { (Le Brun y Díaz 2018) }\end{array}$ & $\begin{array}{c}\text { Traducción } \\
\text { propuesta } \\
\text { (Le Brun y Díaz 2018) }\end{array}$ \\
\hline tronja & $\begin{array}{l}\text { Arcaísmo que } \\
\text { designa un espacio } \\
\text { situado debajo del } \\
\text { tejado de la vivienda, } \\
\text { que se destinaba a } \\
\text { guardar frutos, que- } \\
\text { sos y granos. A veces } \\
\text { también utilizado } \\
\text { como desván. }\end{array}$ & $\begin{array}{l}\text { [...] voilà tout l'atti- } \\
\text { rail obligé que l'éle- } \\
\text { veur place dans une } \\
\text { partie reservée de sa } \\
\text { chaumière, souvent } \\
\text { dans la pièce même } \\
\text { où il couche avec sa } \\
\text { famille, quelques fois } \\
\text { dans un grenier spa- } \\
\text { cieux, si l'éducation } \\
\text { se fait plus en grand. } \\
\text { (2018: 479) }\end{array}$ & $\begin{array}{l}\text { [...] este es todo } \\
\text { el aparejo necesa- } \\
\text { rio que el criador } \\
\text { coloca en una parte } \\
\text { reservada de su } \\
\text { casa a menudo, en } \\
\text { la misma en la que } \\
\text { duerme con su fami- } \\
\text { lia, algunas veces en } \\
\text { una tronja espaciosa, } \\
\text { si la cría se hace en } \\
\text { mayor cantidad. } \\
\text { (2018: 469) }\end{array}$ \\
\hline tunera & $\begin{array}{l}\text { Probablemente se } \\
\text { trate de un andalu- } \\
\text { cismo que designa a } \\
\text { la chumbera. Docu- } \\
\text { mentado en Canarias } \\
\text { desde } 1807 \text {. }\end{array}$ & $\begin{array}{l}\text { Toutefois, la culture } \\
\text { de cette espèce } \\
\text { n’est pas encore } \\
\text { assez généralement } \\
\text { répandue pour que } \\
\text { je puisse assurer si } \\
\text { elle est réellement } \\
\text { préférable á celle } \\
\text { de la tunera sous le } \\
\text { rapport du produit. } \\
\text { (2018: 444) }\end{array}$ & $\begin{array}{l}\text { Sin embargo, el } \\
\text { cultivo de esta espe- } \\
\text { cie todavía no está } \\
\text { lo suficientemente } \\
\text { generalizado como } \\
\text { para que yo pueda } \\
\text { asegurar si realmente } \\
\text { debe preferirse al de } \\
\text { la tunera con arreglo } \\
\text { al producto. (2018: } \\
425 \text { ) }\end{array}$ \\
\hline chochos & $\begin{array}{l}\text { Se trata posi- } \\
\text { blemente de un } \\
\text { andalucismo, que se } \\
\text { extendió a Canarias } \\
\text { y a parte de América. } \\
\text { Designa al altramuz, } \\
\text { tanto a la planta ( } L u \text { - } \\
\text { pinus albus) como al } \\
\text { fruto. Documentado } \\
\text { en Canarias desde } \\
1548 .\end{array}$ & $\begin{array}{l}\text { Dans les campagnes, } \\
\text { où l'on cultive le } \\
\text { lupin, on est dans } \\
\text { l'habitude de leur } \\
\text { distribuer une ration } \\
\text { de cette fève qu'on } \\
\text { a fait cuire dans de } \\
\text { grandes marmites } \\
\text { avec du sel, par deux } \\
\text { ébullitions [...] } \\
\text { (2018: } 380)\end{array}$ & $\begin{array}{l}\text { En las zonas de } \\
\text { campo en las que se } \\
\text { cultivan chochos, es } \\
\text { costumbre distribuir } \\
\text { a los animales una } \\
\text { ración de estas ha- } \\
\text { bas, que se cocinan } \\
\text { en grandes calderos } \\
\text { con sal, después de } \\
\text { hervirlas dos veces } \\
\text { [...] (2018: } 331)\end{array}$ \\
\hline
\end{tabular}




\begin{tabular}{|c|c|c|c|}
\hline faya & $\begin{array}{l}\text { Del portugués faia } \\
\text { (haya), por influen- } \\
\text { cia de la palabra } \\
\text { española, que desig- } \\
\text { na otro árbol. Árbol } \\
\text { miricáceo, muy fron- } \\
\text { doso, cuyos frutos } \\
\text { comestibles sirvieron } \\
\text { para hacer gofio en } \\
\text { otra época (Myrica } \\
\text { faya). Documentado } \\
\text { desde } 1500 \text {. }\end{array}$ & $\begin{array}{l}\text { Le prunier de Lusi- } \\
\text { tanie, les deux Ilex } \\
\text { des Canaries, et } \\
\text { le Faya, sont aussi } \\
\text { des arbres de haute } \\
\text { futaie qui fournissent } \\
\text { des bois précieux; } \\
\text { celui du Faya surtout } \\
\text { se recommande par } \\
\text { sa belle marbrure } \\
\text { qui reproduit toutes } \\
\text { les ondulations de } \\
\text { l'agate. (2018: 536) }\end{array}$ & $\begin{array}{l}\text { El Prunus lusita- } \\
\text { nica, los dos Ilex de } \\
\text { Canarias y la faya } \\
\text { también son árboles } \\
\text { de alto tronco que } \\
\text { dan maderas valio- } \\
\text { sas; la de la faya se } \\
\text { recomienda, sobre } \\
\text { todo, por su her- } \\
\text { moso marmoleado, } \\
\text { que reproduce todas } \\
\text { las ondulaciones del } \\
\text { ágata. (2018: } 523 \text { ) }\end{array}$ \\
\hline papa & $\begin{array}{l}\text { Término proveniente } \\
\text { del quechua que } \\
\text { designa un tubér- } \\
\text { culo comestible y a la } \\
\text { planta solanácea que } \\
\text { lo produce (Solanum } \\
\text { tuberosum). Docu- } \\
\text { mentado desde } 1704 \text {. }\end{array}$ & $\begin{array}{l}\text { La viande de bou- } \\
\text { cherie est pour eux } \\
\text { un aliment de luxe; } \\
\text { la pomme de terre } \\
\text { et le poisson salé } \\
\text { constituent leur plat } \\
\text { de préférence. ( } 2018 \text { : } \\
376)\end{array}$ & $\begin{array}{l}\text { La carne de matanza } \\
\text { para ellos, es un } \\
\text { alimento de lujo, la } \\
\text { papa y el pescado } \\
\text { salado constituyen } \\
\text { su plato preferido. } \\
(2018: 327)\end{array}$ \\
\hline mocán & $\begin{array}{l}\text { Visnea mocanera. } \\
\text { Árbol de la familia de } \\
\text { las y también su fruto. } \\
\text { Su origen es incierto, } \\
\text { pues si algunos } \\
\text { investigadores ven en } \\
\text { fitónimo un término } \\
\text { prehispánico, otros, } \\
\text { al estar igualmente } \\
\text { presente en otras } \\
\text { zonas de la Maca- } \\
\text { ronesia, ven más bien } \\
\text { un portuguesismo. } \\
\text { Documentado desde } \\
1495 .\end{array}$ & $\begin{array}{l}\text { Ces belles forêts } \\
\text { canariennes, que } \\
\text { l'Antiquité célébra, } \\
\text { ces verts bocages où } \\
\text { les lauriers, les mo- } \\
\text { cans, les ardisiers et } \\
\text { tant d'autres espèces } \\
\text { croissaient confon- } \\
\text { dues, se trouvent } \\
\text { réduits maintenant } \\
\text { à quelques groupes } \\
\text { d'arbres entourés de } \\
\text { bois taillis. (2018: } \\
\text { 536) }\end{array}$ & $\begin{array}{l}\text { Estos bellos montes } \\
\text { canarios, que la } \\
\text { antigüedad celebró, } \\
\text { sus verdes boscajes } \\
\text { en los que los lau- } \\
\text { reles, los mocanes, } \\
\text { los adernos y tantas } \\
\text { otras especies que } \\
\text { crecen entremezcla- } \\
\text { das, se encuentran } \\
\text { ahora reducidos a } \\
\text { algunos grupos de } \\
\text { árboles rodeados de } \\
\text { monte bajo. (2018: } \\
\text { 525) }\end{array}$ \\
\hline parra & $\begin{array}{l}\text { En Tenerife, La } \\
\text { Gomera y La Palma, } \\
\text { aguardiente que, por } \\
\text { destilación, se ob- } \\
\text { tiene de las madres } \\
\text { del vino*. }\end{array}$ & $\begin{array}{l}\text { [...] enfin l'eaudevie } \\
\text { blanche des Cana- } \\
\text { ries, qui s'exporte en } \\
\text { damesjeannes à La } \\
\text { Havane et qui sélève } \\
\text { à } 40000 \text { francs, et } \\
\text { quelque fois davan- } \\
\text { tage. (2018: } 147)\end{array}$ & $\begin{array}{l}{[. . .] \text { por último, la }} \\
\text { parra de Canarias } \\
\text { que se exporta en } \\
\text { garrafones a La Ha- } \\
\text { bana y que se eleva } \\
\text { a } 40000 \text { francos y } \\
\text { algunas veces a más. } \\
(2018: 130)\end{array}$ \\
\hline
\end{tabular}




\begin{tabular}{|c|c|c|c|}
\hline destiladera & $\begin{array}{l}\text { Piedra arenisca de } \\
\text { forma semiesférica } \\
\text { ahondada con la } \\
\text { que se filtra el agua } \\
\text { para beber. Designa } \\
\text { también el mueble } \\
\text { que contiene dicha } \\
\text { piedra, el bernegal y } \\
\text { el jarro para beber. } \\
\text { Documentada desde } \\
\text { 1743. Término igual- } \\
\text { mente utilizado en } \\
\text { América }\end{array}$ & $\begin{array}{l}\text { [...] nos bâtiments } \\
\text { de commerce } \\
\text { viennent charger } \\
\text { chaque année á } \\
\text { Sainte Croix de } \\
\text { grandes quantités } \\
\text { de pommes de terre, } \\
\text { d'oignons, d'aulx, de } \\
\text { pierres à filtrer et de } \\
\text { dalles qu'ils portent } \\
\text { au Sénégal [...] } \\
\text { (2018: 404) }\end{array}$ & $\begin{array}{l}\text { [...] nuestros buques } \\
\text { mercantes vienen } \\
\text { a cargar cada año a } \\
\text { Santa Cruz grandes } \\
\text { cantidades de papas, } \\
\text { de cebollas, de ajos, } \\
\text { de destiladeras y de } \\
\text { losas, que se llevan a } \\
\text { Senegal [...] (2018: } \\
355)\end{array}$ \\
\hline malpaís & $\begin{array}{l}\text { Compuesto léxico } \\
\text { formado en Cana- } \\
\text { rias sobre una base } \\
\text { francesa (pays), que } \\
\text { designa un terreno } \\
\text { de lava y también la } \\
\text { lava que lo forma. } \\
\text { Forma documentada } \\
\text { desde } 1420 \text {. }\end{array}$ & $\begin{array}{l}\text { Il existe dans ces îles } \\
{[\ldots] \text { d'immenses }} \\
\text { nappes de lave que } \\
\text { les habitans appelent } \\
\text { malpais (mauvais } \\
\text { pays) [...] (2018: } \\
477)\end{array}$ & $\begin{array}{l}\text { Existen en estas islas } \\
\text { inmensas coladas } \\
\text { de lava que los habi- } \\
\text { tantes llaman mal- } \\
\text { país (2018: 467) }\end{array}$ \\
\hline \multicolumn{4}{|c|}{$\begin{array}{l}\text { El lema parra no aparece registrado en el DHECan, por lo que la información } \\
\text { indicada se ha extraído del Diccionario básico de canarismos de la Academia } \\
\text { Canaria de La Lengua (DCan). }\end{array}$} \\
\hline
\end{tabular}

En el caso de los fitónimos, tan abundantes en esta obra, se ha optado por conservar el nombre científico en la traducción: «Pero se pueden destacar también dos magníficas mirsináceas, que mezclan sus ramas con el Prunus lusitanica, el Rhamnus glandulosa, el Ilex canariensis y un Viburnum, que sustituye en estos verdes bosquecillos a nuestro sauco europeo.» (2018: 521), aunque se acompaña en anexos una tabla que ofrece las denominaciones vernáculas de las especies.

\section{Conclusiones}

Dada la especial naturaleza de los escritos gubernamentales, la traducción de documentos consulares, destinada a la vez a un público general y a uno especializado, exige un proceder traductológico excepcional, a caballo entre la traducción comercial y la traslación literal. En el caso concreto de los informes y memorias consulares redactados por Sabino Berthelot entre 1847 y 1874, dicha excepcionalidad se ve incrementada por la relevancia de la que gozó la figura de su autor en las islas Canarias, así como por la trascendencia de sus escritos científicos y políticos, en muchos casos, pioneros en su época. En aras de lograr reestablecer en español la polifónica voz del texto fuente, con la mayor fidelidad 
posible, se ha llevado a cabo una labor de peritaje lingüístico, más propia de filólogos que de traductores. Este posicionamiento metodológico ha exigido la adopción de la modalidad lingüística canaria como norma traductológica, lo que, sin ninguna duda, constituye una excepción en la práctica traductiva.

\section{Bibliografía}

Almeida M. y Díaz Alayón C., 1998, El español de Canarias, Santa Cruz de Tenerife.

Berthelot S., 1840, De la pêche sur la côte d'occidentale d'Afrique et des établissements les plus utiles aux progrès de cette industrie, París, Ed. Bethune.

Berthelot S., 1879, Antiquités canariennes, París, Ed. Plon.

Berthelot S. y Barker Webb, Ph., 1835-1850, Histoire naturelle des îles Canaries, París, Ed. Bethune.

Catalán D., 1989, «El español en Canarias», in El español, orígenes de su diversidad, Madrid, p. 145-201.

Collombat I., 2012, «Traduction et variation diatopique dans l'espace francophone: le Québec et le Canada francophone», Arena Romanistica-Journal of Romance studies, Universidad de Bergen, p. 13-50.

DCan $=$ Varios autores, s. f., Diccionario básico de canarismos. Academia Canaria de la Lengua, disponible en www.academiacanarialengua.org, [consultado el $15 / 01 / 19]$

DHECan = Corrales Zumbado C., Corbella Díaz D., s. f., Diccionario Histórico del Español de Canarias, <http://web.frl.es/DHECan.html>, consultado el $12 / 01 / 19$.

Gaviño de Franchy C., 2010, «José Desiderio Dugour: un naufragio afortunado», $<$ http://lopedeclavijo.blogspot.com/2010/08/jose-desiderio-dugour.html>, consultado el 07/01/2019.

Le Brun N., 2016, Un francés entre guanches. Sabino Berthelot y las Islas Canarias, La Orotava, LeCanarien Ediciones.

Le Brun N. y Díaz Rodríguez C., 2018, Informes y memorias consulares de Sabino Berthelot (1847-1874), La Orotava, LeCanarien Ediciones.

Lorenzo A., Morera M. y Ortega G., 1996, Diccionario de canarismos, Santa Cruz de Tenerife.

Mayoral Asencio R., 1999, La traducción de la variación lingüística, Soria, Diputación Provincial de Soria, colección «UERTERE. Monográficos de la revista HERMÉNEUS».

Newmark P., 1992, Manual de traducción, Madrid, Cátedra.

NGLE = Real Academia Española y Asociación de Academias de la Lengua Española, 2009, Nueva gramática de la lengua española, Madrid, Espasa Libros. 
Nougaret Ch. y Parinet E., 2015, L'édition critique des textes contemporains (XIX ${ }^{{ }^{-}}$ XXI ${ }^{e}$ siècle), París, École nationale des chartes, «Magister».

Mayoral Asensio R., 1999, «La traducción de la variación lingüística», Uertere, Monográficos de la revista Hermeneus, $\mathrm{n}^{\circ} 1$, Soria, Universidad de Valladolid.

Ortega Ojeda G., 2016, El español hablado en Canarias, Santa Cruz de Tenerife, Consejería de Educación, Universidades, Cultura y Deportes del Gobierno de Canarias. Dirección General de Ordenación e Innovación Educativa, <http://www3.gobiernodecanarias.org/medusa/mediateca/ publicaciones/?attachment_id=2599>, consultado el 14/01/2019.

Oustinoff M., 2003, La traduction, París: Presses Universitaires de France.

Reiss K. y Vermeer H., 1996, Fundamentos para una teoría funcional de la traducción, Madrid, Akal.

Seleskovitch D. y Lederer M., 2014 [1984], Interpréter pour traduire, París, Les Belles Lettres, $5^{\mathrm{a}}$ edición.

Tous Meliá, J., 2013, «Alexandre Bretillard: medio siglo al servicio de Francia 1796-1847», La Prensa del domingo-Revista Semanal de El Día, p. 1-3.

Uclés Ramada, G., 2016, «La traducción de las referencias a la variedad diatópica en el doblaje español», Normas 6, p. 77-92. 